\title{
Teaching Economics Principles as Part of Development Studies
}

John Cameron, Ken Cole and Chris Edwards ${ }^{1}$

\section{The Context of Development Studies and the Necessity of Theory}

Development studies is centrally concerned with change in all aspects of societies, arguably changes in the whole world economy. Thus, insofar as conventional knowledge is concerned with equilibrium and divides experience into firmly delineated disciplines, there is an immediate problem of commensurability between the language of understanding and that of explanation. It is possible for an acute observer to understand a situation using the language of those directly affected; to explain it appears to require experiments by scientists using a technical language of theory. This problem was seen initially as a failure of a particular discipline. For instance, Randall Baker wrote in the early 1970 s on geography in development studies

there has been a tendency in the past (which this article is perpetuating!) for geographers to speak to the converted by researching and publishing within the almost closed system of geography. By the incorporation of geography into the School of Development Studies, the subject will have to interact with other disciplines, and its contribution will be judged in the market place alongside other social sciences. [Baker 1973: 279]; emphasis added-the irony of the emphasised phrase will become apparent.

But, by the mid-1970s, everyone had taken a glance at each others' disciplines and decided they all had problems. For example, Tony Barnett and Deryke Belshaw reported in 1975 on teaching together about rural development as a sociologist and an economist respectively:

The paradigms of these disciplines (mainstream economics and sociology) are so different, however. that an integrated macro-theory does not seem possible on this basis. It may be useful in future to introduce more detailed case studies earlier in the

\footnotetext{
1 This article is the result of research work carried out by the authors whilst teaching principles of economics in the School of Development Studies. Whilst Athole Mackintosh would not have agreed with all the points here, we feel it owes much to the spirit of critical enquiry he himself brought to bear on the subject. The argument has been carefully developed as an undergraduate textbook entitled The Political Economy of Economics, to be published by Longmans in 1981.
}

course specifically to demonstrate the limitations of each single discipline.

[Barnett and Belshaw 1975: 14] our parenthesis.

The understandable response to this finding has been a tendency to abandon the disciplines altogether and move towards case studies as a teaching device. This response encouraged a number of positive changes in the practice of teaching development studies. These included increased student participation as lecturers were forced to admit the inadequacy of theory, and the use or more local-and hence more accessible-material, thus diminishing the 'Third World' exclusiveness of development studies. Both student participation in the education process and the use of local material are important steps forward in our view, and we feel these advantages can be generally maintained without abandoning rigorous theory and retreating into ex post rationalisations of unrepeatable incidents. Economics has suffered much for early arrogance in claiming priority in the field of development studies. The path through dualism, two-gap models, take-off, unbalanced growth, export-led growth, trickle-down and dependence, is one along which economics has stumbled proclaiming constantly that this time the calculations were correct. Economists are now notorious as people who not only have apparently insurmountable differences but also are capable of all being wrong simultaneously. In such a context, it is a brave teacher who says that principles of economics in a School of Development Studies should be about 'principles' of a rigorous discipline. But this is what the authors have been doing for the last three years and they feel able to claim that the insights their approach give are important to understanding social change in the world today. At the end of the article are listed a few of the books and articles we have found useful in the past (Appendix I).

\section{Confused Unity or Clear Conflict}

That economics has particular problems can be illustrated by the treatment of two issues which are of some interest to all economists concerned with development-the issues of 'growth' and 'inflation'. The following are some of the areas of ambiguity and disagreement on these issues: definition of terms (eg does 'inflation' include wage level changes?); problems of priority (eg is stopping price rises the most important government goal?); problems of imputing causality (eg what is 'the cause' of a price rise?); and 
closely related problems of how to test the theories (eg if one economist says wage rises cause price rises and another says that price rises cause wage rises, how can one adjudicate between the explanations?).

Economists interested directly in underdevelopment are acutely aware of these problems, as their participation in planning and aid agencies in underdeveloped countries apparently has given them a great deal of influence. But their sensitivity to the problem has not produced strong guidelines for sorting wheat from chaff. For example, Michael Todaro writes:

A careful selection of appropriate economic concepts and principles adapted to the realities of these nations is not only desirable but essential to an adequate understanding of the way in which economics can contribute to Third World development.

[Todaro 1977: 62]

This apparently unexceptionable statement becomes inoperable when people have to agree on what are 'reality', and 'development', let alone on whether 'nations' and the 'Third World' are meaningful starting points!

\section{Avoiding the Issue in Standard Textbooks and Blaming Politicians}

In the two introductory textbooks which have dominated the field of economics teaching over the part 15 years, the authors conclude in the following unsatisfactory way on the two issues referred to earlier, 'inflation' and 'growth':

Certain theories have been put forward. One is that periods of very high demand and mild inflationary pressures are beneficial to growth. It is argued that such periods provide the businessman with both the incentive to invest and the funds (which can be withheld out of profits) with which to finance the investment. Another theory says that periods of moderate excess capacity, with an absence of inflationary pressures, are most conducive to growth. The argument here is that, when there is some unemployment in the economy, resources for new investment will be readily available, and that innovations in terms of new products or cost reductions in old ones provide the only possible promise of large profits. As yet we really do not know enough to choose between them.

[Lipsey 1971: 705]

Is there a tendency for price levels to rise even when a sizable and undesirable level of unemployment persists? If there is such a modern tendency, then pollcy decision becomes hard, and compromises may be necessary. 'Price stability is a prerequisite for growth.' 'Growth is a prerequisite for reasonable price stability'. 'New mechanisms for an incomes policy must coordinate free collective bargaining'. 'Some price creep may at times be the necessary compromise that must be made in the interest of growth and tolerably high employment'. These are varying views among which citizens and statesmen must today choose.

[Samuelson 1967: 777]

So the student reading 15 hundred pages of these two texts finds that on two of the crucial issues of the day, all the analysis has produced is statements which are either ambiguous or non-commital. But all around the student, people, including those who call themselves economists, are firmly taking positions which show both directness and commitment. At the end of a year of studying economics, students cannot be blamed for thinking that they have learnt nothing about the rough and tumble of the world outside. Also some of the more astute may well be suspicious that a statement like 'the division between macroand micro-economics is not a matter of right and wrong but rather a matter of convenience' [Lipsey $1971: 435$ ] is not even particularly rigorous. Thus, failing from the points of view of application and logic, economics can easily seem irrelevant and arbitrary, and from the student's point of view, boring and confusing.

Of course, nobody expects to learn a difficult subject in a year, but unless the student is treated with respect at the start then there is a strong disincentive to discontinue the study of the subject or not treat it seriously. Students know that economists disagree, that incoming governments bring in their 'own' economic advisers and that in most universities and colleges there are obvious disagreements between faculty - not just on detail but on fundamental principles. And yet the texts they are faced with blandly assure them that in many cases of disagreement, 'further research could lead to a consensus of opinion' [Lipsey 1971: 722] and that

the reader who has persisted this far now has a general knowledge of the economic analysis that is used all over the world-in the United States, Britain, Western Europe, Latin America, Africa, and Asia. The tools of economic analysis, developed and tested over more than a century, are turning out to have an applicability beyond the range of economics narrowly defined. In the hands of scholars like Michigan's Kenneth Boulding, they are applied to the pressing problem of conflict resolution and struggle; in countless departments ofoperations research, and in the Pentagon military establishment itself, they are being used to increase the efficiency of executive decision making. Like a gun, which can be used to defend a home or bully a harmless stranger, these tools have an efficiency whose final contribution to welfare must depend on how they are used and by whom. They also have a certain austere aesthetic grace.

[Samuelson 1967: 793]

In contrast, our approach takes seriously both the disagreements among economists and the students' 
experience of such discord. There are no efforts to paper over cracks by concealing conflict. Neither do we wish to set up any case as simply a target to be knocked down. Fights over policy are shown to have roots in deep conflicts over the essential nature of human activity. These conflicts not only divide economists, but run right through contemporary societies. The sphere of knowledge we call economics has been peculiarly, but not uniquely, split. Economics is especially interesting in development studies because its central concern is with 'valuation' in its widest sense. Economists have found it impossible to stand back from pronouncing on the way to achieve improved states of society. Some 'economists' claim only to present 'politicians' with objective evaluations of the likely outcome of policies, but in such cases we would argue that the 'economist' must adopt the basic assumptions of the 'politician' about the valuation of social activity or communication will break down.

For example, the analysis by several leading economic forecasters of the 1979 UK budget, showed to be: increasing unemployment, higher inflation, lower economic growth and a rise in an already substantial balance of payments surplus in the coming year, as compared with the predicted outcome if the government had done nothing. These economists now in the wilderness, no longer connected with policy decisions, because their whole concept of using such indicators to evaluate a state of society was under challenge from a view (backed by many other economists) that the state of UK society must be valued in a very different way. On the new view whether these economists were wrong in their calculations was not the argument: what was wrong were the principles of valuation that gave those particular calculations any great significance. Economists, then, may be forced to choose whether to go into the wilderness with principled politicians of similar values when power is lost, or stay close to power but only at cost of changing principles. Multi-principled people may well exist, but history suggests that the line between the multi-principled and the confused and unprincipled may be difficult to discern. In trying to serve all masters, an economist will fail to achieve the confidence and respect of any; in serving one, an economist may fail to achieve any influence or effectiveness in policy making. Keynes, whose own experience-from influence to (well-cushioned) wilderness, to influence again-gave good reason to reflect on the relationship between economics and power, wrote at the end of his major work:

Practical men, who believe themselves to be quite exempt from any intellectual influences, are usually the slaves of some defunct economist.

[Keynes 1967: 383]

Whilst this thought is comforting to economists out of influence, more worrying and probably more accurate would be an amended version along the lines:
Defunct economists are usually slaving to bring themselves to the attention of practical men.

\section{Why Economics is Important: Valuation as a Central Concern}

All the efforts of economists to pass themselves off as a profession standing above the political fray, capable of passing disinterested judgment on the petty disagreements of politicians, have foundered on internal dissension and not on external criticism. So, in economics at least, dog does eat dog, but not indiscriminately. There is some pack loyalty between dogs of similar breed. Our investigations over the last five years have identified three pure breeds (described below) which form a basis for successful in-breeding and are capable of giving rise to all the cross-breeds we have seen in the past. Unfortunately, the mongrels have always proved to have dysfunctional characteristics-crosses between bulldogs, greyhounds and pekinese are unlikely to be successful! In our view, the only link between these three groups of economists is their concern with valuation. Of course, the generality of this term allows a variety of interpretations, and most of these interpretations have been emphasised by people calling themselves economists.

The particular perspective that an economist brings to human activity is a judgement of its worth. This judgement may be only qualitative (eg that a job is socially unproductive), or relative (eg this good is worth more than that) or absolute (eg my fee is $\$ 200$ a day for that service). Bound up with any judgement ot worth is a theory of how value comes into existence, ie what is the cause of value. Armed with such a theory it is possible both to describe what is happening in society and to prescribe what should be done to achieve a worthier (or more developed) state of society. It is this ability to describe and link that description to prescription that is crucial to the emergence of a distinct school of thought with the ability to survive. Description implies a matching with some part of experience; increasingly this matching has emphasised experiments by economists rather than observation by people, but appeals to self-evident truths and common sense are still made in order to justify theories. If such a description is deficient, then the theory can be called 'utopian' in that, while it may suggest a desirable future, it fails to link that future with observed present, thus losing the support of those who consider themselves 'realists'.

The step from description to prescription implies the application of reason-that is, we can only agree on action if the links between activity and outcome are clear. Reason implies an agreed set of rules about the nature of the links and economists have emphasised the rules of logic, increasingly in the form of 
mathematics, although some have implicitly indicated scepticism about the limiting of economics to issues which can be formulated mathematically. Without clear links of reason, then theory runs the risk of 'inconsistency' and thus losing its appeal to those who consider themselves 'rationalists'. Lastly, without prescription a theory can give no guide to policy and thus is unattractive to those who consider themselves 'activists', in the sense that they believe in our power to change the world for the better.

A theory which offends against realists, rationalists and/or activists is unlikely to thrive in present day society, whereas one which appeals to all three has a good chance of survival. All three of our schools of economic thought do meet these criteria for survival. Each points to an area of experience as matching its description, carefully displays the logic of its arguments, and arrives at policy conclusions. But, in the past, judgements of valuation and worth were not the prerogative of people called economists but belonged to other people, often calling themselves bishops and kings. Theology has always concerned itself with value and worth, as has the study of the exercise of justice. For economists to gain predominance required a change in society which came with the development of exchange through relatively anonymous markets. The market gives the experience of not being governed by representatives of either gods or kings. The extension of markets into more and more areas of life was thus a revolutionary, and in many ways liberating, experience for the mass of people, and a threat to vested interests. The expression of this experience in the realm of ideas was a shift towards justifying the valuation of activities by reference to markets and prices. But, since those who have the privilege of time to write down ideas are often closest to old vested interests, the intellectual support of the market as an independent source of value was slow in developing.

Mercantilists and physiocratic writers in Europe in the sixteenth and seventeenth centuries showed confusion over valuation in the market as against previous moral and political bases of valuation. But in the thought of Adam Smith in the eighteenth century, value as revealed in the market place was raised to a dominant position. Even though valuation in the market place never completely displaced values in the pew (ie moral judgements) or on the hustings (ie judgements based on power), it has raised economists to prominence. Thus the position of economists as theorists of valuation has become increasingly strong. But our research has identified three different theories of valuation put forward by economists. (This parallel development of competing theories is shown in diagramatic form in Appendix II.)

\section{The Subjective Preference Theory of Value}

Adam Smith focused attention on the market as the primary location of valuation but failed to provide an unambiguous explanation of the origin of such value even though he generally approved of its results. The links between acceptance of market valuation and justification of market valuation have been developed by a series of writers stretching from Smith's time to our own-such as Jevons, Fisher, Hayek and Friedman. The common basis of their thinking we have termed the subjective preference theory of value. The starting point for this theory is the individual, endowed with tastes, talents and rationality, who calculates actions so as, to maximise personal welfare, or in technical terms, utility. The individual's tastes define preferences between alternative consumption patterns including leisure. The individual's talents, on the other hand, define an ability to fulfil these desires, through productive activity. Thus tastes lead to consumption and talents lead to production. Where productivity is increased through a specialist division of labour, then there is an apparent separation between the individual as consumer and as producer. The link between these two spheres is exchange in markets, with relative rates of exchange being determined by the individual's relative utility derived from the consumption of more goods at the expense of less leisure. These decisions are coordinated using a special talent, called entrepreneurship, which combines inputs in order to maximise the personal utility of such talented individuals through maximising profit. Inputs can be grouped as labour services (ie negative leisure) and capital services (ie postponed consumption), both of which cost utility to the supplier. The rewards that individuals get can consist of profit, as the return to the organising talent of the entrepreneur; wages for other workers; and interest for those who loan resources to entrepreneurs.

The independence of the individuals within the economy means that society is seen as the sum of the individuals that compose it. Society is the product of individuals, and as such the analysis of social forces is irrelevant, as is any historical analysis of social development. Social behaviour consists therefore of relating to others through exchange because of differential tastes or talents. Where there is free exchange there is no contradiction between the individual interest and the social interest, since no-one has to enter into an exchange if it is not in their interest so to do. Thus a voluntary equilibrium situation can be deduced where individuals pay in utility terms in supplying productive inputs, and receive according to the utility they gain from consuming products. Value is determined in consumption, in the sense that productive activity is only undertaken if 
consumption is desired. Since the dynamic of the system is the maximisation of individual utility, the policy implications that follow are designed to create an institutional environment which allows maximum freedom for individual decisions. Thus the role of the state is to provide the apparatus for the enforcement of contracts in free markets.

This implies a profound objection to active government intervention in the economy, and scepticism over the significance of aggregate relationships, as in Friedman [1977] and Brittan [1975]. The values of the free marketplace reveal themselves as prices to which each individual is at liberty (a vital word) to respond independently of the power of others. Of course, many economists have proclaimed a fundamental confidence in the market process as the best way of ensuring the greatest happiness for all, but desired to qualify that support on some particular issues-perhaps health or education. For the purposes of this argument we are not concerned with treating such qualifications in detail, but try to show the basis of the unifying fundamental confidence. It is a rather daunting thought that, whenever an economist talks uncritically about supply and demand in a market, behind those apparently uncontroversial terms lies the assumption of a whole philosophy of possessive individualism, liberal politics and the basic tenets of modern civilisation. But it does perhaps make a little more interesting.

Why did people wait so long to discover this desirable way of organising social activities? Human experience up to 1750 appears largely a waste of time if free markets are the key to wellbeing. The answer for subjective preference theory lies in the change of thinking which occurred at about that time in Europe and North America, which is known as the Enlightenment. Intellectual energy was diverted towards understanding what we might do on earth now, rather than what we might do to regain a glorious past or achieve a heaven in the future. By ceasing to ask 'why' some of the time and asking 'how' instead, enormous changes were quickly made to the physical world and new possibilities discovered in the relationship between individuals and society. The problem with asking 'how' and not 'why' is that knowledge becomes more tentative, as well as more powerful. Making statements about how a market works if left to its own devices assumes that the audience accepts that those statements are likely to apply in the future and in different places.

The point that present knowledge is always tentative is central to the philosophy of Karl Popper, who is something of a doyen among leading subjective preference theorists. His position is that, providing a theory can be exposed to a test of falsification through observation, it can stand as explaining how the observation was generated. This position on the nature of 'scientific' knowledge is consistent with subjective preference theory because it renders the untestable assumptions about individualism unimportant compared with predictions about observable market behaviour. Unfortunately, there is a temptation to cross the line between saying 'the world acts as if it were composed of independent individuals' to 'the world is composed of independent individuals'. But the use of mathematics, and its relationship to complex statistical experiments, has given subjective preference theory a firm methodological base, in addition to its philosophical roots. The theory has a durable strength which goes beyond fashion and particular economists; it thus can claim an independent existence and can be spoken of as an actor in its own right.

\section{The Cost of Production Theory of Value}

But to recognise that valuation in the market is significant does not necessarily make it desirable. The optimism about the market system which developed into subjective preference theory was met almost at its moment of historical conception by a profound pessimism which was to give economics the lasting label of the 'dismal science'. This pessimism appeared in Smith's writing as a concern with the psychological impact of routine, monotonous work on the human mind, but in the hands of David Ricardo in the early part of the nineteenth century the pessimism became more profound. Ricardo started from the proposition that, whilst value appears in the market, it originates and changes with the rewards that must be paid for inputs into production. Labourers must receive sufficient to live, and capitalists (ie those who provide resources for labourers to work up) must receive a return in addition to their original outlay if production is to expand. Malthus introduced two assumptions about the nature of the physical world: first, that the population of labourers grows if resources are available to feed it, and, secondly, that the productivity of a given bundle of labour and resources falls as more and more land is brought into use.

Under these assumptions, the market process produces stagnation as a final equilibrium condition, with the mass of the population living at a level of bare physiological subsistence facing a group of landowners conspicuously consuming all the rest of society's resources. It is this central concern with the production decision, the distribution of output between the 'contributors' to production, and the tendency to stagnation (usually measured in numbers of unemployed) if market forces operate alone, that 
distinguishes an approach to valuation we have called 'the cost of production theory of value' which is exemplified by Marshall, Veblen, Keynes and Galbraith. In its purest form, the theory starts from the fact that people combine to undertake production in an increasingly complex and inflexible fashion. Social relations are therefore largely determined by the needs of technology rather than voluntary exchange; a technology which, like the tastes, talents and propensities of the subjective preference approach, is given from outside economics.

This technology changes as people learn more about the physical world and these changes put new requirements on people to change their behaviour. The problems of adjustment may come from a number of sources. First, decentralised decisionmaking may mean that the inter-connections between producers break down when general change is required. Secondly, the ideas and institutions that people develop to organise themselves for production and distribution may lag behind the possibilities or requirements of the new situation. For instance, markets which involve considerations about the future, eg stock and financial markets-which are so crucial to decision-makers in industry where a new technology may take five years or more to come into full operation-are notoriously liable to violent fluctuations or breakdown. Thirdly, even if stagnation is avoided, this may only be at the price of granting disproportionate power to a small group of production decision-makers whose particular interest may differ from those of the rest of society. Thus, whilst cost of production theory accepts that value appears as market prices, it sees the source of that value in production adjusted by distributional factors and is sceptical about prices as the final measure of social value.

For example, 'silicon chip' technology offers new opportunities for higher output or higher unemployment, and also higher profits or higher wages. For cost of production theory, the precise outcome will depend on a social response to these opportunities far wider than those industries which happen to be most amenable to the introduction of the new technology. Most strikingly (!), if the technology is controlled by a few industrialists, or vulnerable to action by a small group of workers, then their distributional gains may diminish the advantages to society as a whole. But, more generally, the resources for investment in new equipment and retraining of displaced workers will require mobilisation on a scale which will disrupt markets because, as value is determined at the point of production for this theory, the response of prices to dramatic changes in production processes will also be dramatic.
But if one concludes that change cannot be achieved by anonymous market forces without risking high unemployment, due to a lack of belief in subjective preferences as the stabilising force of consumer demand, and that change is also vulnerable to distortion in the interests of small groups of people, then how can society as a whole benefit from new technology? For contemporary cost of production theory, Ricardo's pessimism has its antidote in the representative state and a disinterested bureaucracy rising above particular interests for the benefit of the whole society. The writings on inflation and growth by Balogh [1970], Kuznets [1965] and Beckerman [1971] demonstrate these principles in action. Detailed state intervention is not only necessary if the economy is to continue but is also possible because of the stability and predictability of several crucial relationships at the level of the whole economy which are unstable at the level of the individual. Thus alongside and complementing the cost of production theory of value, are the pluralist theory of politics-which analyses conditions for compromise and power broking-and sociological theories of bureaucracywhich analyse the conditions for and limitations of effective action in large organisations.

Whilst the general principles of cost of production theory do show continuity, in that they start from production as given, analyse distribution as a problem and end with a rationale for state intervention, the precise content of theory has changed with technology. For the cost of production theory this is totally consistent, since economics is a social institution with its own vested interests, especially as practised in universities, and so will not only have to change but will also possess the conservatism that other institutions have when faced with change. This conservatism has received a formal statement in the concept of 'paradigms' put forward by Thomas Kuhn. Broadly this concept draws attention to the tendency for groups of intellectuals to become totally absorbed in the logical puzzles of a particular theory. When outside change occurs, then the intellectuals have to be wrenched reluctantly back from metaphysical speculation to the problems of the real world, and a new theoretical formulation, or paradigm, may be necessary. Change and adaptability are therefore required and pragmatism is a virtue in that prompt reform may avoid confrontation and avert collapse. For instance, a theory suitable for an economy of owner-managers will not necessarily apply to an economy based on large joint-stock corporations. The common theoretical ground from Ricardo to Galbraith is explicable on the grounds that technology is a 'non metaphysical' starting assumption, unlike utility in subjective preference theory and exploitation in abstract labour theory, and that the 
basic categories of distribution (wage, profit and rent) have remained largely unchanged.

\section{The Abstract Labour Theory of Value}

Ricardo's lack of confidence in the market system coexisted historically with the development of 'socialism' as a set of ideas and political activities. Smith's positive evaluation of capitalism was criticised on moral grounds, due to the poor living conditions of the mass of factory workers, and on political grounds because increased repression seemed necessary to maintain the system. It was the work of Karl Marx which linked valuation in the market to this previous rather utopian critique of capitalism by self-labelled socialists. The rigorous aspect of Marx's thought was to refuse to assume that any aspect of human activity was to be treated as given, eg tastes and technology, and yet still manage to say something about the nature of valuation as society changed. For the abstract labour theory of value it is thus assumed that the structure of demand is determined by changing social convention and that techniques of production are changed as a response to changing social relationships, not just as a result of evolving knowledge of nature. As moral and political valuations also change over time, valuation cannot be on the basis of saying capitalism is invariably evil or violent but more that it is out-dated historically.

When people combine to produce, they do so in social relationships which are not simply dictated by technical requirements but involve considerations of power and status. The whole structure of production, distribution, exchange and consumption reflects these relationships. One such relationship is the commodity relationship in which people relate to each other through markets using money. This relationship has become dominant in a type of society Marx called capitalist which historically appeared when large numbers of people were no longer able to produce without first selling their working ability to someone else. In such a situation there is the possibility in the abstract that more work effort may be sold by the workers than the effort embodied in the goods that the workers require to provide that work effort (the concept of 'exploitation'). In that gap between what the worker requires and what the worker can give lies the possibility of profit accruing to capitalists for whom the workers must work in order to live.

What turns this possibility into reality is not the avarice of capitalists but their own struggle for survival. Profit appears as money, not as a collection of physical goods, and employers must show adequate profits if they are to survive. The valuation of machines, buildings and stocks in money terms varies with changes in social conditions, usually with a downward trend, as rivals bring in changes to reduce the mount of effort required per unit of output (which was over-simplified in Ricardian terms as a reduction in amount of labour time required) thus forcing each capitalist towards new innovation or bankruptcy. Thus pressure on individual capitalists also comes from commodity relationships and, in general, capitalism is subject to the tension that downward pressures on profit rates exert. This point of view underlines the position of Arrighi [1978] and Bullock/ Yaffe [1975]. Thus in the abstract labour theory of value, the apparent paradox - that in spite of vastly increasing output there is increasing conflict in capitalist societies-is resolved. Capitalism can never rest on its achievements and is always in danger of destroying itself, but the question remains whether another social relationship develops within capitalism-remember that central to the materialist rigour of this theory of value is that nothing comes from outside experience, whether it be a deus ex machina, the seventh cavalry, or the Bolshevik Party-which can build on the inherited material affluence.

This question raises the crucial issues of the relationship of the abstract labour theory of value to action, and its self-justification as scientific knowledge. The term 'dialectics' with connotations of inherent, irresolvable, structural contradictions leading to basically unforeseeable change, is useful here. But at a more immediate level, it was Marx who said that the job of philosophers was to change the world, and certainly self-avowed Marxists like Lenin and Mao Tse-tung have answered that job description. The underlying tendency or logic of capitalism, an abstract reality in the mind, arising from the 'law' of value which commodity relations produce, can only be assessed by the effectiveness of political decisions at the level of class struggle, a concrete reality in the mind. The notion of praxis expresses this tension between theory and practice and, for the abstract labour theory of value, the praxis has been how to mobilise those aspects of working class experience which deny commodity relationshops (eg collective, cooperative work) as the basis of working class politics. This project can be judged as successful in explaining the development of capitalism through imperialism, wars and depressions, and thus the $a b-$ stract labour theory of value has gained intellectual credibility, but insofar as its adherents have failed to produce a society which transcends commodity relationships, then abstract labour theory still has some way to go to meet its own criterion of success.

\section{To Learn One Theory of Economics is Quite Bad Enough!}

This is an understandable response to this article as a basis for teaching economics. Some students cer- 
tainly have wished we had made our minds up which was 'best' and devoted our meagre talents to an exposition of that theory alone. Our answer takes us beyond the basic credibility criteria of rationalism, realism and activism which we suggested above towards a more comparative framework. The ideas of the three schools have not developed in vacuo but in relationship with each other. Writers have stimulated and goaded each other into strengthening and developing their theories. The ferocious energy which has been put into debates that seem esoteric to the non-economist can be understood in this light. Each theory can be seen as having a set of core propositions to defend against criticism, and barriers are erected against attacks which also become areas of theoretical development. The struggle to advance, and stop retreats becoming routs, forms the theories, and as time goes on the core propositions of each theory are more likely to be revealed. Thus to understand one theory completely requires some knowledge of the others.

As, in general, core propositions are those least amenable to empirical investigation, then reference to observations are unlikely to help rank the theories. Even if in principle a test can be designed, there are many ways in which test results can be queried. For instance, have the assumptions of the theory been met, and are the observations accurate and statistically adequate? The limits of empiricism are frequently discussed by social scientists, but the discussions too often are couched in terms of 'thinkers who don't observe' versus 'observers who don't think'. Of course, this dichotomy is ridiculous and may conceal the real issue that some propositions do not lend themselves to easy experimental testing.

In similar vein, it is understandable that, as divisions in the subject become more obvious, the belief should gain support that if only the 'facts' could be examined in a disinterested way, then a new economics would emerge. Whilst such a response can be sympathised with, there is the remaining problem that gathering 'facts' requires some preconceptions of where to look and what to look for. This preliminary organisation is, in effect, primitive theory and it seems likely that such a primitive theory will imply a more sophisticated theory that will closely resemble one of the theories already available.

Observation and measurement do not offer, therefore, an obvious solution to the question of choosing between theories. Also the central cores of propositions are unlikely to fail a test of logic. Any effective attack on these propositions has thus to be on the essential nature of the propositions as foundations of scientific knowledge. Unfortunately the term 'science' is as elusive as the term 'economics'. Amid a philosophical jungle of epistemological bases, ontological statuses, and teleological determinisms, a student may feel nostalgic for the friendly forest of economics. Our investigations of the theory of knowledge as currently practised have convinced us that it offers little help in choosing between the three theories of value. Such philosophy provides a language for description which is precise, but stops short of giving clear criteria for naming a sub-set of knowledge as 'scientific' beyond the rationalism, realism and activism criteria which all three theories of value meet.

But what of our own claim at least to see the divisions, even if we stop short of immediately selecting one as superior. This apparent arrogance may well owe something to the personalities of the authors but has other explanations which situate this approach in a wider context. We have already suggested above that, as time has passed, the conflict between the theories was likely to reveal the deeper disagreements between economists. In addition, there is a general perception that economic problems in the UK have been exceptionally acute in the 1970s, compared with other economies. Also, in general, world politics have become noticeably more ideological in content in the last few years compared to the proclaimed pragmatic reformism and convergence theories of the 1960s. Thus in time and location the authors and their students stand in a peculiarly privileged position. The analysis in this article is partly a contribution to current debates, in that it tries to present each major case in its purest and strongest form. In order to fulfil this objective completely, however, it is important to use this framework to face the whole range of policy issues which are on the agenda of world politics at this time, and show the coherence of various positions by reference back to the general points of principle. Thus we view the principles of economics, as laid out here, as necessary but insufficient for a full development studies course. The course as we have taught it lasted for about one third of the students' first year and, although we would naturally have liked more time to develop the ideas, we consider this to be adequate, provided the principles are explicitly built into later courses of a more problem-oriented type.

\section{References}

Arrighi, G., 1978, 'The roots of the present recession'. New Left Review, no 111

Baker, P. R., 1973, 'Geography in development studies at the University of East Anglia', Area, vol 5 no 4 
Balogh, T., 1970, 'Labour and Inflation', Fabian Tract 403

Barnett, A. S., and D. R. G. Belshaw, 1975, 'Rural development: one approach to interdisciplinary teaching, in Case Studies in Interdisciplinarity, Nuffield Foundation

Beckerman, W., 1971, 'Why we need economic growth', Lloyds Bank Review, no 102

Brittan, S., 1975, 'Participation without politics', Hobart Paper Special 62, Institute of Economic Affairs, London

Bullock, P., and D. Yaffe, 1975, 'Inflation, the crisis and the postwar boom', Revolutionary Communist, November

Friedman, M., 1977, 'Inflation and unemployment', Occasional Paper 51, Institute of Economic Affairs, London

Keynes, J. M., 1967, The General Theory of Employment, Interest and Money, Macmillan

Kuznets, S., 1965, Economic Growth and Structure, Heinemann

Lipsey, R. G., 1971, An Introduction to Positive Economics, Weidenfeld and Nicholson

Samuelson, P. A., 1967, Economics, McGraw-Hill

Todaro, M. P., 1977, Economics for a Developing World, Longman

\section{Appendix I: a preliminary bibliography of useful writing in the field}

Critique of empiricism:

Hollis, M. and E. Nell, Rational Economic Man, Cambridge University Press, 1975
Lenin, V. I., Materialism and Empirio-criticism, Peking, 1972

Williams, K., 'Karl Popper's empiricism', Economy and Society, vol 4 no 3, pp 309-58

For and against logical positivism and subjective preference:

Friedman, Milton, 'The methodology of positive economics', in Essays in Positive Economics, pp 3-43, Chicago, 1935

Balibar, Etienne, 'Positivism and irrational thought' in New Left Review, no 107, pp 3-20, 1978

Nell, Edward, 'Economics: the revival of political economy', in Rogin Blackburn (ed), Ideology in Social Science, Fontana/Collins, 1975

For and against paradigms and cost of production:

Kuhn, Thomas S., The Structure of Scientific Revolutions, Chicago, 1975

Blaug, M., 'Kuhn versus Lakatos', in History of Political Economy, 1975

Rowthorn, B., 'Neo-Classicism, Neo-Ricardianism and Marxism', New Left Review, no 86, 1974

For and against dialectical historical materialism and the abstract labour theory of value:

Lenin, V. I., The Three Sources and Three Component Parts of Marxism, Progress Publishers, 1976

Popper, K., The Poverty of Historicism, Routledge and Kegan Paul, 1974

Robinson, Joan, An Essay on Marxian Economics, Macmillan, 1967 


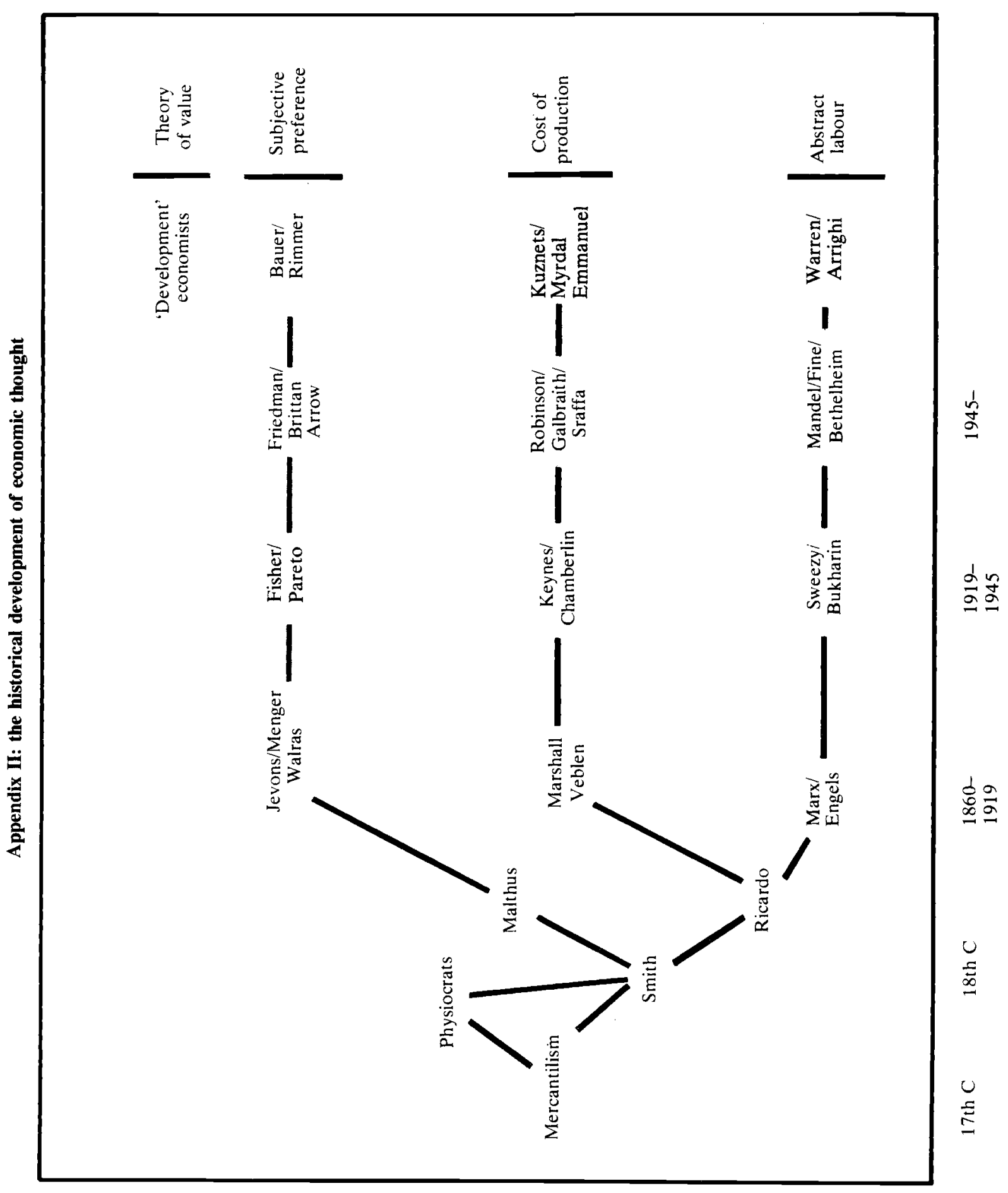

